\title{
Evaluating Seismic Hazard Map for Specified Seismic Source Fault Using GIS-based 3D Deterministic Model: a Case Study of Low Seismicity Region in Egypt
}

Ibrahim DJAMALUDDIN ( $\square$ ibedije@gmail.com )

Hasanuddin University: Universitas Hasanuddin https://orcid.org/0000-0002-2963-1899

Poppy Indrayani

Fajar University: Universitas Fajar

Ahmed M. Meneisy

Aswan University

\section{Research Article}

Keywords: Earthquake, seismic hazard map, deterministic method, ground motion, spatial model, GIS

Posted Date: February 11th, 2022

DOI: https://doi.org/10.21203/rs.3.rs-1248750/v1

License: (c) (i) This work is licensed under a Creative Commons Attribution 4.0 International License.

Read Full License 


\section{Evaluating seismic hazard map for specified seismic}

2 source fault using GIS-based 3D deterministic model: a

3 case study of low seismicity region in Egypt

4

5 Ibrahim DJAMALUDDIN $^{\mathrm{a}, \mathrm{b}^{*}}$, Poppy INDRAYANI ${ }^{\mathrm{c}}$, Ahmed M. MENEISY $^{\mathrm{d}}$

6

$7 \quad{ }^{a}$ Department of Environmental Engineering, Faculty of Engineering, Hasanuddin

8 University, Poros Malino KM 6, Bontomarannu, Gowa Regency 92171, Indonesia

9 Email address: ibedije@gmail.com

10

${ }^{b}$ Disaster Risk Reduction Research Center, Faculty of Engineering, Kyushu University,

12744 Motooka Nishi-ku Fukuoka City 819-0395, Japan

13 Email address: ibrahim@doc.kyushu-u.ac.jp

${ }^{\mathrm{c}}$ Graduate School of Engineering, Fajar University, Prof. Abdurahman Basalamah No.101, Makassar City 90231, Indonesia

17 Email address: poppyindrayani@yahoo.com

${ }^{d}$ Faculty of Science, Aswan University, Sahary City, Airport Road, Aswan 81528,

20 Egypt

21 Email address: ahmedmeneisy@sci.aswu.edu.eg

*Corresponding author,

25 Ibrahim Djamaluddin (Dr., Associate Prof.)

26 Tel: $(+62) 8122231975$

27 Email address: ibedije@gmail.com 


\section{Abstract:}

Although Egypt may be considered as an area of low seismicity, it has experienced the recurring destructive effects of earthquakes throughout its history. The damage distribution is significantly affected by fault geometry and the local site effects. Thus, an appropriate assessment of seismic hazard became a major challenge for efficient mitigation of the seismic risk. This study develops the Geographical Information System (GIS) based three-dimensional (3D) deterministic model to evaluate the seismic hazard map for specified seismic source fault for Egypt. The geometry of a fault plane is generated by a fault-modeling algorithm in which multiple 3D plane sets are interpreted by fault trace, geology, and topography. For estimating the local site effects, the study area is modeled by a 3D grid-mesh system and the ground motion propagation is estimated at each grid by considering the spatial analysis of average shear-wave velocity and a soil susceptibility map. The developed model is applied to simulate the seismic hazard maps in particular the October 12, 1992, Dahshour earthquake that caused huge disasters. The simulated seismic hazard maps of the October 12, 1992, Dahshour earthquake are validated at the observation of an isoseismal map and the evidence of the locations that caused serious damages. Furthermore, an evaluation of the expected Dahshour earthquake with magnitude 6.5 and October 11, 1999, Beni Suef earthquake is conducted for seismic risk mitigation study. By utilizing the developed model, our results encourage the GIS approach for seismic hazard analysis where 3D models can lead to a more accurate assessment.

Keywords: Earthquake; seismic hazard map; deterministic method; ground motion; spatial model, GIS 


\section{Introduction}

Earthquakes are one of the dangers of natural disasters that can pose risks to human life, loss of property, and environmental damage (Cornell 1968). Tectonic earthquakes occur anywhere on earth where there is sufficient stored energy of elastic strain to promote fracture propagation along the fault plane. The mechanism of destruction occurs because the energy release patterns and shaking effects are propagated to all parts of the earth. On the earth's surface, the shaking can cause damage and collapse of buildings that can cause casualties, and can also trigger landslides, rock collapses, and other soil damage that destroys residential areas. The earthquake also causes secondary disasters in the form of fires, industrial and transportation accidents, and floods due to the collapse of dams and other retaining embankments. In general, earthquakes will damage and destroy densely populated villages with weak building construction, non-earthquake resistant buildings with poor technical design, high-rise buildings built on poor soil conditions, and buildings on unstable slopes (Mohamed et al. 2012).

The size of the magnitude scale describes the amount of seismic energy emitted by the earthquake source and the results of seismograph observations. The magnitude of an earthquake with a scale of 3 or less often cannot be felt on the surface or is called weak. The magnitude scale of 7 or greater will potentially cause serious damage in an area. However, earthquake disaster is not dependent only on the magnitude scale but also on the effect of local sites (Abdel-Fattah 1999). Seismic hazard is the probability that an earthquake will occur in a given area and quantification of the seismic ground motion at a specific site. Seismic ground motion level is typically high in the vicinity of the fault plane and decreases with distance from the fault depending on the earthquake magnitude and the geology of the region ( $\mathrm{Si}$ and Midorikawa 1999). The effect of local sites especially the soft soil layer is the main factor in the intensity of the earthquake shaking because it can amplify the seismic ground motion (Hough et al. 1990; Sabet et al. 2015). For instance, although Egypt may be considered as an area of low seismicity, it has experienced the recurring destructive effects of earthquakes throughout its history (Badawy, 1998). The Dahshour earthquake of October 12, 1992, and the Beni Suef earthquake of October 11, 1999, are well-known examples of a small but affecting earthquake disaster in beneath southwestern Cairo, the northern part of Egypt. Because 
most of the dense populations, archaeological sites, and vital infrastructures are concentrated around the Nile river valley which is covered by sedimentary soil layers, and the majority of buildings are not yet designed to resist earthquakes; therefore, even relatively small ground motion can be the source of huge disasters. Several earthquake events in the world have occurred in the past, such as the earthquakes in Michoacan, Mexico in 1985 Loma Prieta, California, the USA in 1989, Kocaeli and Düzce, Turkey in 1999, Chi-Chi, Taiwan in 1999, and Wenchuan, China in 2008, reminds us of the significant disasters influenced by the effect of local sites (Borja-Navarrette et al. 1986; Hough et al. 1990; Rathje et al. 2003, 2005; Wen et al. 2010). Hence, an appropriate assessment of the seismic hazard map is a critical element in the earthquake risk management process for Egypt.

In recent years, many studies have been carried out on the calculation of seismic ground motions by the application of models (e.g., Boore 1983, 1996, 2003, Ambraseys 1995; Joshi et al. 2007; McGuire 1995, 2008; Mustafa and Takenaka 2009; Khaled et al 2013; Ordaz et al. 2014). The calculation models can be classified mainly into two approaches. A deterministic calculation approach is applied from a given specified set of seismological parameters, including the determination of specified fault as an earthquake source and distance from the fault to the points at the ground surface for calculating the seismic hazard by attenuation relationships. The probabilistic calculation approach is used to estimate statistically seismic hazards using all possible earthquake sites, magnitudes, and expected probabilities of occurrence. In low seismicity regions for example in the northern part of Egypt, the assessment of seismic hazard using a probabilistic calculation approach must cope with difficult identification of active seismic faults with the low amount of seismic data or some regions without seismic records are available (Badawy 2005). The deterministic calculation approach has important implications for effective earthquake risk management in southwestern Cairo such as El Faiyum, Girza, and Beni Suef areas. Appropriate calculations of the seismic ground motion are required to reliably determine a seismic hazard map. Nevertheless, seismic hazard assessment using a deterministic calculation approach is not an easy and timeconsuming task (McGuire 1995; Joshi et al. 2007). The focus is generally on determining the specified seismic source fault at the site through the mapping of the fault rupture plane (i.e. fault length, fault dip, fault depth), the estimation of the ground motion propagation 
125 from geological and soil conditions, and the utilization of the ground motion attenuation

126 relationships to simulate the distribution of seismic hazard.

127 It is essential to compute a deterministic seismic hazard map in three-dimensional (3D)

128 model parameters and to provide automation, intellection, and visualization in the

129 scenario-based simulations for Egypt. Moreover, the spatial quantification of the various

130 ground effects at a specific site is an important analysis of the ground motion propagation

131 for a study area. The recent development of Geographical Information Systems (GIS)

132 comprises a technology designed to support integrative modeling and to conduct

133 interactive spatial analysis for understanding various 3D processes (Fortheringham and

134 Wegener 2000). In the present study, a deterministic calculation model using GIS that

135 realistically computes the seismic hazard map for specified seismic source fault is

136 established to obtain a reliable evaluation of seismic risk for Egypt. A fault modeling

137 algorithm in GIS is developed for generating a 3D fault geometry interpreted by fault

138 trace, topography, and geology. A grid-mesh system in GIS is utilized as a 3D model

139 parameter to estimate the ground motion propagation in the study area by considering the

140 spatial analysis of average shear-wave velocity and the soil susceptibility map. For a

141 preliminary assessment, the ground motion attenuation relationships by $\mathrm{Si}$ and

142 Midorikawa (1999) are adopted to establish the 3D seismic calculation modeling

143 algorithm using GIS functions for evaluating several scenario earthquakes in the study

144 area. The developed model is applied to evaluate the seismic hazard maps for the

145 Dahshour earthquake and Beni Suef earthquake based on a scenario study.

\section{2. Seismic Source Faults in Egypt}

\section{$148 \quad 2.1$ Historical earthquake sites}

149 The study area (Fig. 1) is located in the northern part of Egypt as a part of the Nile 150 river valley, which covers southwestern Cairo including the El-Faiyum, Girza, and Beni 151 Suef areas. According to Badawy and Horvath (1999a, 1999b), most of the earthquake 152 events mainly occur in the northern part of Egypt and are related to the plate boundaries.

153 The relative motion of the Sinai sub-plate concerning the Suez rift and to the Aqaba-Dead 154 Sea rift characterizes the major source of seismic activities in the northern part of Egypt. 155 A relatively low rate of historical earthquake activity also continues on-trend to the 
southwest Beni Suef area. Fig. 2 represents the study area remarked by dotted lines and selected historical earthquakes from 1990 to 2018 beneath southwestern Cairo that has

158 been the important site of several earthquake events, in particular, a magnitude 5.9

159 Dahshour earthquake struck about 40km southwestern Cairo on October 12, 1992, caused 160 tremendous damage.

\section{$161 \quad 2.2$ Geological and tectonic setting}

162 Geology of the study area has been investigated by a variety of authors (e.g. Hume 1911; Said 1962; Said and Martin 1964). The study area is mostly covered by sedimentary rocks of different formations belonging to the middle Eocene up to the Quaternary. Generally, the geological formations are composed of Mokattam Group, Wadi Rayan Formation, and shallow marine limestone (Sabet et al. 2015). In the Nile river valley, sediment formations are classified into three types: the Protonile consists mainly of gravel, the Prenile consists of fluvial sand, and the Nile silt consists of fine clastic sediments. According to the Egyptian Geological Survey and Mining Authority (EGSMA) in 1981,

170 Egypt was subjected to several stages since the Precambrian. The Precambrian is characterized by the development of three main fault directions, North-South (N-S), North Northwest-South Southeast (NNW-SSE), and Northeast- Southwest (NE-SW). In the Paleozoic, a new East-West (E-W) trend developed and continued to affect the Mesozoic. The Mesozoic folding structures known in the northern part of Egypt were also affected by a new fault trend in East-Northeast (ENE) and West-Northwest (WNW) directions. The Red Sea became effective in the Northwest- Southeast (NW-SE) and NE-

177 SW trends. Fig. 3 shows a simplified geologic map from Egyptian General Petroleum

178 Corporation (EGPC) which depicts the different rock formations in the vicinity of the

179 Nile river valley, and the relief map describes the major trend of lineaments. Rose 180 diagram (see Fig. 3) reveals that the dominant trend of lineaments tends to run NW-SE 181 and NE-SW. These lineament trends are in correspondence with the previously obtained 182 trends by Badawy and Horvath in 1999.

\section{$183 \quad 2.3$ A 3D fault modeling algorithm in GIS}

184 The most simplistic method for 3D fault modeling is a simple flat plane. By setting a 185 dip and azimuth the inferred fault can be created. However, if the case involves multiple 186 faults that intersect or consist of multiple parts of a fault plane, manual fault mapping is 187 labor-intensive and time-consuming to determine 3D models (Admasu et al. 2006). In 
this study, automatic fault mapping is accomplished by using multiple spatial datasets interpreted by fault trace, geology, and topography.

190 Fig. 4 shows the simplified algorithm of fault modeling using GIS functions that represent several spatial analyses dan data manipulation to create the $3 \mathrm{D}$ fault model. At

192 the first stage, the spatial analysis and data manipulation are conducted to obtain the

193 multiple datasets of surface z-values interpreted by fault traces and ground surface contour data by Digital Elevation Model (DEM). Subsequent fault calculating fits a surface contour to the highlighted fault dip through the spatial analysis from the geological data. Azimuth Line Points are calculated using the Near Analysis in GIS by interpreting the surface contour and fault trace-points to obtain the calculation of azimuth angles. Azimuth angles at each trace-point are central parameters to estimate the fault shape through a spatial calculation using a mathematical formulation. The second stage of the calculation is conducted to estimate the multiple datasets at irregularly spaced locations by the Dip Line Points. Fault surface searches for a connected, smooth curve with fits the subsurface dataset. This result is then projected to the next inline, providing fault planes. In this stage, the Dip Line Points generates two sets of data points on one side of the ground surface and the other side of the subsurface. Thus, a smooth surface between the two sets of data points is computed by the Triangular Irregular Network (TIN) Analysis. Moreover, the Point Inter-Line is calculated from the Azimuth Line Points that uses to select the calculated orientation of each triangular face of a 3D TIN polygon (fault plane) for example, N-E dip or S-W dip. Finally, fault plane results on a series of successive dataset sections, constitute a 3D fault model by the format of 3D polygon shapefile in the GIS dataset.

211 In the computational implementation system, the 3D fault modeling is accomplished

212 by the use of GIS geoprocessing tools. Fig. 5a shows the actual stages of the schematic

213 flow model of geoprocessing tools that comprises a 110-step process to provide an 214 automatic computation of 3D faults for speeding up interpretation on large 3D datasets.

215 The developed schematic flow model is represented as a diagram that chains together 216 sequences of processes using the output of one process as the input to another process.

217 Accordingly, an adjustment model for 3D fault planes can be performed by only changing 218 the input parameters without going through a long-stage process. Fig. 5b shows the 3D 219 view of a 3D fault modeling resulting from the selected fault traces (lineaments) beneath 
southwestern Cairo, the northern part of Egypt, as an example of the result from GIS geoprocessing tools.

\section{Ground motion propagation}

\subsection{Ground motion records in the study area}

Observed areas of building damage in southwestern Cairo resulting from October 12, 1992, Dahshour earthquake might be related to the ground motion propagation within the Nile river valley which is covered by sedimentary soil layers (Ahmed et al. 1993). However, the opportunity to capture recorded ground motion data from the earthquakes in the northern part of Egypt was lost primarily because of the lack of strong motion instrumentation, inadequate geographic coverage of instrumentation networks presently installed, and inadequate dynamic range of the seismographic instrumentation in place

232 (Thenhaus et al. 1993). Lacking the ground motion records, there is always the question of whether anomalously located areas of damage are due to deficient construction practices or an actual physical enhancement of ground motion propagation.

\subsection{A 3D grid-mesh system for site amplification factor}

It has been recognized by researchers that soft and young sediments covering firm bedrock can amplify seismic ground motions and cause severe damages during an earthquake event. The shear-wave velocity of shallow sediments is very important in ground motion propagation. Anderson et al. (1986) noted that the strata in the top 30 meters have a considerable influence on the character of the created seismic ground motions. The average shear-wave velocity from the surface to 30-meter depth (AVS or Vs30) is a well-known parameter for estimating the site amplification factor (ARV).

Table 1 shows the definition in terms of AVS and simple geological descriptions by the

National Earthquake Hazard Reduction Program (NEHRP). The ARV between surface and firm bedrock has the following relationship with AVS, described as Eqn. 1.

246 (Midorikawa 1994)

$247 \log \mathrm{ARV}=1.83-0.66 \log \mathrm{AVS}$, for $(100<\mathrm{AVS}<1500)$

248 where,

ARV: the site amplification factor for peak ground velocity $(\mathrm{m} / \mathrm{s})$

AVS: the average shear-wave velocity from surface to $30 \mathrm{~m}$ depth $(\mathrm{m} / \mathrm{s})$ 
In this study, the AVS dataset from the United States Geological Survey (USGS) is used to obtain the AVS contours interpolated from grid points at a 5-kilometer scale as a proxy for the spatial analysis of the site amplification factor. Since the AVS values should

254 be used at finer scales for the study area, the soil susceptibility map by 1:50,000 scale and

255 the interpolated AVS contour map are utilized further by spatial correlation analysis to estimate the AVS at a 50-meter grid scale. This soil susceptibility map is generally based on the distribution of shallow soil profiles over rock beneath the Nile river valley. Fig. 6 shows the estimated ARV map of the study area that lower shear wave velocities (200 to $250 \mathrm{~m} / \mathrm{s}$ ) correspond quite well with the outcrop of unconsolidated Quaternary sediments along the Nile river valley (see Fig. 3). The areas consist of soft-stiff sediments like Nile silts that are more susceptible to amplification.

In the GIS calculation model, the 3D grid-mesh system (see Fig.5b) is used for seismic hazard simulations that will define the accuracy and resolution of the simulation results, both of which will affect the GIS computation time and level of detail in the results of the seismic hazard map. Therefore, it's important to have a site amplification factor that is linked in the 3D grid-mesh for computational simulation. Grid-mesh involves the ground elevation and a site amplification factor to represent the arrangement and spacing between each grid point. The study area which varies in elevation across different mountain ranges or complex surface geological boundaries may require high meshing density to ensure accuracy, which increases the computation time in the simulation. In this study, a rectangular grid by 50-meter is designed to represent the study area for use in a seismic hazard simulation. The result of the estimated ARV map and DEM map are interpolated for the entire simulation domain which has 5,548,164 of the total grids.

\section{Hazard assessment method}

\subsection{Ground motion attenuation relationships}

277 To calculate the seismic hazard for specified seismic source fault in 3D model 278 parameters, the attenuation relationships defined by Si and Midorikawa (1999) are 279 utilized as a preliminary assessment model. The methodology of attenuation relationships 280 used are described as follows:

281 a) Peak ground acceleration (PGA) 

that occurred during earthquake shaking at a specific site. The PGA is calculated by the distance attenuation formula of peak acceleration with shear wave velocity (Vs $=400$ $\mathrm{m} / \mathrm{s})$, described as Eqn. 2. where,

PGA: peak ground acceleration $\left(\mathrm{cm} / \mathrm{s}^{2}\right.$ or gal)

$$
\mathrm{M}_{\mathrm{m}} \text { : moment magnitude }
$$

d: fault types

b) Peak ground velocity (PGV)

Peak ground velocity (PGV) is the maximum respective amplitudes of velocity at the ground surface. The attenuation relation of peak velocity on the bedrock with shear wave velocity $(\mathrm{Vs}=600 \mathrm{~m} / \mathrm{s})$ is given as Eqn. 3. By multiplying Eqn. 1 and Eqn. 3, the PGV at the ground surface is described, as Eqn. 4.

300 where,

c) Seismic intensity (SI)

304 Seismic intensity (SI) is calculated using the relation between the intensity and the peak ground velocity, described as Eqn. 5.

$306 \mathrm{SI}=2.68+1.72 \log \mathrm{PGV}$, for $(4 \leq \mathrm{I} \leq 7)$

307 where,

\section{SI: seismic intensity}

\subsection{D calculation modeling algorithm in GIS}

310 There are two spatial datasets of the input parameter for conducting a computational

311 process of the seismic hazard assessment within GIS. The first dataset is 3D polygons as

312 a fault geometry model, and the second dataset is a $3 \mathrm{D}$ grid-mesh system as a ground

313 motion propagation model. Other parameters such as earthquake magnitudes, hypocenter 
314 depth, fault types, etc. are specified in the 3D polygon dataset. The 3D seismic hazard 315 calculations are performed within GIS. The function of GIS is used as a spatial-temporal 316 database for extracting, calculating, and updating the input data.

317 Fig. 7 shows the algorithms of the 3D seismic hazard calculation model for specified 318 seismic source fault. By the functions of GIS, the operator interface of point collection 319 (IPointCollection) read the input of the 3D polygon of fault model in the computational system of GIS to access and manipulate the Polygons. IPointCollection can be used to create Multipoints from polygon vertices in 3D return references to the points in the collection. Multipoints containing $x, y$, and $z$ values are used to calculate the fault plane equation of a polygon. Assume that a polygon is given by its vertices $v 1, v 2, \ldots, v n$, in cycle order, and each $v i$ is given by its coordinates in 3D: $v i=(x i, y i, z i)$. The fault plane equation, $A x+B y+C z+D=0$ is given by the equation of vectors. By computing the fault plane equation of a polygon, $A, B, C$, and $D$ can be obtained. New coordinates for each polygon vertex and plane angles can be computed by using the formula and operator interface to provide the coordinate conversion process from global to the local projected system in GIS. Operator interface of geometry (IGeometry) and proximity

330 (IProximityOperator) is applied to define the sides of the polygon and the projected polygon and to compute the distances $\left(L_{f}\right)$ from points to points in the polygon, sequentially. IProximityOperator is also used to calculate the nearest points from the gridmesh system as ground motion calculation points (ground surface points) to the projected polygon points. The formula of the calculation of real distance is established to compute the real height distance $\left(L_{h}\right)$ from the calculated fault point to the ground surface. To obtain the shortest distance $(L s)$ from a surface point to the $3 \mathrm{D}$ polygon (fault plane), nine cases of the mathematical algorithm are developed which depend on the position of fault sides to the calculation points and the parameters of $L_{f}$ and $L_{h}$. Generally, the shortest distance $(L s)$ from $\left(x_{0}, y_{0}, z_{0}\right)$ to the $3 \mathrm{D}$ polygon plane $A x+B y+C z+D=0$ is given by

340 following formula.

$L_{s}=\frac{\left|\mathrm{A} x_{0}+\mathrm{B} y_{0}+\mathrm{C} z_{0}+\mathrm{D}\right|}{\sqrt{A^{2}+B^{2}+C^{2}}}$

342 Accordingly, a GIS-based computational model arrays the result of shortest distance 343 values for all the point coordinate at the designed 3D grid-mesh system for each 3D 344 polygon, and calculates the seismic hazard based on the earthquake parameters (Fig. 8). 


\section{Hazard assessment case studies}

There are three scenarios for the seismic hazard simulation in the study area. Case 1 is to validate October 12, 1992, Dahshour earthquake with magnitude 5.9. The 3D fault model used in the present study is derived from the 1992 Dahshour mainshock, estimated by Hussein et al. (1996) with specific parameters (depth of epicenter is $22 \mathrm{~km}$, fault depth to the upper edge is $12 \mathrm{~km}$, length of fault is $12 \mathrm{~km}$, width of fault is $10 \mathrm{~km}$ ), and main fault orientation is $270^{\circ}$ (strike) and $47^{\circ}$ (dip). Case 2 is to assess the maximum expected Dahshour earthquake with a magnitude of 6.5. Case 3 is to evaluate October 11, 1999, Beni Suef earthquake with magnitude 4.9. The 3D fault model is interpreted with specific parameters (depth of epicenter is $26 \mathrm{~km}$, fault depth to the upper edge is $15 \mathrm{~km}$, length of fault is $5 \mathrm{~km}$, width of fault is $12 \mathrm{~km}$ ), and main fault orientation is $153^{\circ}$ (strike) and $72^{\circ}$ (dip) (Abou-Elenean and Deif 2003).

\section{Results and Discussion}

A similar study of October 12, 1999, Dahshour earthquake has been conducted by several researchers (Hussein et al. 1996; Hussein 1999; Hussein and Farouk 2000; Abou Elenean et al. 2000; Moustafa and Takenaka 2009; Khaled et al. 2013). The stochastic approach is mostly used to calculate the peak ground acceleration (PGA). The rectangle fault plane is subdivided into an appropriate number of sub-faults which are modeled as point sources, and the site amplification factor is not yet considered in the seismic hazard map for Egypt. In this study, seismic hazard simulations have taken several procedures, which range from the development of various kinds of spatial datasets that permit the interpretation of the specified earthquake fault sources in $3 \mathrm{D}$, the estimation of the local site effects including soil and topography to input in the 3D grid-mesh system, and the $3 \mathrm{D}$ calculation of the shortest distance by the attenuation relationships for simulation accuracy. Seismic hazard simulations including the peak ground velocity calculation and seismic intensity calculation were established to evaluate the detailed distribution areas for each hazard level in the study area. The simulation of seismic hazard maps for the Dahshour earthquake and Beni Suef earthquake were performed that assume scenarios for the rupture of a seismic source fault by previous studies. Although there is a lack of validation studies in the region, the $3 \mathrm{D}$ input parameters used for the seismic hazard maps 
are fruitful to be based for reliable disaster risk reduction in the region. The detailed

377 results of the seismic hazard maps are described in two following sections.

\section{$378 \quad 6.1$ The Dahshour earthquake}

379 The first step of analysis includes the validation of the simulation model of the October

38012,1999 , Dahshour earthquake at the observation of isoseismal map according to the

381 MMI scales, as currently available data. Fig. 9 shows the location of the designed

382 simulation region for evaluating seismic hazard maps as a study area marked by a red

383 dotted line that overlaid with the isoseismal map of the MMI observation of October 12,

384 1992, Dahshour earthquake, established by Thenhaus et al. in 1993. The isoseismal map

385 represents the contours of the highest predominant MMI levels about the observed

386 building damages on the west side of the Nile river valley including the areas of El-

387 Faiyum, Girza, and Beni Suef, in the study area. According to Thenhaus et al. (1993), the

388 earthquake on October 12, 1992, occurred in Dahshour with the highest of the MMI level

$389 \quad(\mathrm{MMI}=\mathrm{VIII})$ that caused tremendous damage performing major disaster in the Nile river

390 valley. The observed soil liquefaction near the earthquake epicenter (MMI = VIII)

391 occurred in the alluvial Nile deposits at many sites near the Barnasht to El Aiyat Districts

392 (Japanese Expert Team 1993; Ahmed et al. 1993). On the isoseismal map, the seismic

393 intensity distributions ranging from level VI to level VII are mostly located in Cairo, El

394 Faiyum, Girza, and also Beni Suef. Serious building damage areas were investigated in

395 Cairo, El-Faiyum, and Girza. On contrary, no building and infrastructure damage was

396 observed in the Beni Suef area. Fig. 10a shows the simulation result for peak ground

397 velocity. The distribution of the maximum respective amplitudes of velocity at the ground

398 surface that exhibits some low (dark green to green colored) and moderate (light green to

399 yellow colored) values, and reveals a prominent very strong level (MMI = VII-VIII) as

400 major damage areas, located in the front area of the rupture propagation of the Dahshour

401 fault. Table 2 shows the statistical result of surface velocity distribution at each MMI

402 level. The ranges of the observed MMI are compared by the simulated model. Moreover,

403 Fig. 10b shows the simulation result of the distribution of the seismic intensity map

404 overlaid by the smoothed contours (dotted lines) from the isoseismal map representing

405 the highest predominant intensity levels of MMI. The overall concentration and

406 distribution of seismic intensity calculated are mostly consistent with the MMI

407 distribution levels. The largest misfit is observed in the low-intensity range (MMI V). 
However, it is sometimes difficult to identify whether the reason for the misfit of each intensity range is site amplification or attenuation relationships. Taking into account the

410 seismic hazard maps of the October 12, 1992, Dahshour earthquake, the overall

411 agreement between the simulated and observed is satisfactory according to the seismic

412 hazard distributions and the locations of the observed serious damage areas. The

413 simulated model indicates the detailed distribution of seismic hazard levels than the 414 observed MMI contours. For example, the distribution of low hazard levels in the Beni 415 Suef area can be identified more precisely.

416 Moreover, Fig. 11a-b shows the simulation results of a scenario study of seismic 417 hazard maps by a maximum expected magnitude 6.5 Dahshour earthquake. The seismic 418 hazard areas beneath southwestern Cairo are greatly increased by about more than double 419 that indicated by the detailed distribution of peak ground velocity and seismic intensity 420 levels. Predictably, the effects could be much worse in Cairo, Girza, and El Faiyum than 421 those experienced in the 1992 Dahshour earthquake. In addition, the potential for 422 widespread liquefaction is very high on the Nile floodplain near the village of Manshiyat423 Fadil. Accordingly, the disaster risk mitigation in the northern part of Egypt should be 424 measured by maximum expected seismic hazard maps that are valuable to evaluate the 425 earthquake-resistant design of structural buildings as well as land-use planning in the 426 future. The developed seismic hazard map can estimate the potential damages in the study 427 area that needs to be investigated further.

\section{$428 \quad 6.2$ The Beni Suef earthquake}

429 The first event of October 11, 1999, the Beni Suef earthquake was the largest observed 430 earthquake to occur in the Beni Suef area. The maximum observed intensity of MMI 431 levels was VI at the epicenter and IV at the Beni Suef area (Abou-Elenean and Deif 2003).

432 Fig. 12a-b shows the simulation of the distribution of the surface velocity and seismic 433 intensity for the October 11, 1999, Beni Suef earthquake. Relatively high seismic 434 intensity near the fault and along the Nile river valley is identified because of strong 435 motions raised from spatial distance factors to site amplification. According to 436 Midorikawa (2006), large ground motion variations near faults for inland crust 437 earthquakes are caused by fault propagation effects or the heterogeneous distribution of 438 asperities. The higher values of the seismic intensity are mostly observed along the Nile 439 River covered by alluvial lowland zones. This seismic hazard map allows the 
440 identification of the detailed distribution of hazard levels affecting a given site in the Beni

441 Suef area. The simulation result shows that the Beni Suef area lies at a relatively high 442 hazard because of the increased ground motion propagation. Consequently, the site 443 amplification requires detailed investigations of each geologic setting. Although there is 444 a lack of relevant studies in the study area, the developed seismic hazard maps can be 445 used for evaluating seismic risk from future earthquakes in the region. The results of this 446 study describe that the GIS-based 3D calculation model is useful to simulate the 447 distributed hazard levels for the Beni Suef earthquake. For more suitable assessment, 448 detailed site-specific amplification and attenuation relationship studies are very important.

\section{Conclusion}

451 The evaluation of seismic hazard maps for specified seismic source faults in the northern part of Egypt is conducted in GIS. The fault model is developed using multiple spatial datasets interpreted by fault trace, geology, and topography. A schematic flow of fault modeling using geoprocessing tools are established for automatic computation of numerous spatial analysis and data manipulation to obtain the $3 \mathrm{D}$ polygon dataset as the 3D fault model parameter. The site amplification factor is estimated from the average shear-wave velocity and soil susceptibility map of the study area through spatial analysis in GIS. Moreover, the 3D grid-mesh system is used as a domain computation for the ground motion propagation model parameter. By implementing the functions of GIS, a $3 \mathrm{D}$ modeling algorithm using the attenuation relationships is conducted to calculate the seismic hazard for all the points coordinated at the 3D grid-mesh system.

The results of this study accomplished the simulation of the seismic hazard of the 463 October 12, 1992, Dahshour earthquake, the scenario study for the maximum expected magnitude 6.5 Dahshour earthquake, and the October 11, 1999, Beni Suef earthquake. The simulation of the 1992 Dahshour earthquake is validated at the observation of the MMI distribution of the isoseismal map and the reliability of the simulated model is verified by comparing the evidence of the observation areas that caused serious damages. The overall agreement between the simulated and observed is satisfactory. Simulation result of October 11, 1999, Beni Suef earthquake also describes that the study area lies at a relatively high hazard because of the increased ground motion propagation in particular 
471 along the Nile river valley. Accordingly, the results of the developed seismic hazard map 472 are more effective in evaluating future seismic risk mitigation for Egypt.

473

474

475

476

477

478

479

480

481

482

483

484

485

486

487

488

489

490

491

492

493

494

495

496

497 


\section{References}

499 1) Abdel-Fattah AK (1999) Source characteristics of the 28th January 1999 Nagano

$500 \quad$ earthquake, Japan. Bull Int Inst Seism Earthq Eng (IISEE) 35:45-57

501 2) Abou-Elenean, KM, Hussein HM, Abu El-Ata AS, Ibrahim EM (2000)

502 Seismological aspects of the Cairo earthquake, 12th October 1992, Ann Geofis 43:

$503 \quad 485-504$

504 3) Abou-Elenean KM, Deif AG (2003) Seismological Aspects and Source Parameters

505 of Beni Suef Earthquake on 11 October 1999. Bull Fac Sci Cairo Univ. 70:120-142

506 4) Admasu F, Back S, Toennies K (2006) Autotracking of faults on 3D seismic data J

$507 \quad$ Geophys 70:49-53

508 5) Ahmed WE, Mohamed A, Korhan (1993) A Liquefaction During October 12, 1992,

509 Egyptian Dahshure Earthquake. In Proc of Int Conf on Case Histories in

$510 \quad$ Geotechnical Eng, 14-18

511 6) Ambraseys NN (1995) The prediction of earthquake peak ground acceleration in

$512 \quad$ Europe. Earthq Eng Struct Dyn 24:467-490

513 7) Anderson JG, Bodin P, Brune NJ, Prince J, Singh SK, Quaas R, Onate M (1986)

514 Strong ground motion from the Michoacan, Mexico Earthquake. Sci 233:1043-

$515 \quad 1049$

516 8) Anon. (1987) Egyptian General Petroleum Corporation (EGPC), Geologic map of 517 Egypt

518 9) Anon. (1993) Report of Japan disaster relief team on the earthquake in Arab,

519 Republic of Egypt of October 12, 1992. Japan International Corporation Agency $520 \quad$ (JICA), p 89

521 10) Badawy A (1998) Earthquake hazard analysis in northern Egypt. Acta Geod Geoph $522 \quad$ Hung 33:341-357

523 11) Badawy A, Horvath F (1999a) Sinai subplate and kinematic evolution of the 524 northern Red Sea. J Geodynamics 27:433-450

525 12) Badawy A, Horvath F (1999b) Seismicity of the Sinai subplate region: Kinematic 526 implications. J Geodynamics 27:451-468

527 13) Badawy A (2005) Seismicity of Egypt. Seismol Res Lett 76:149-160 
14) Boore DM (1983) Stochastic simulation of high-frequency ground motions based on seismological models of the radiated spectra. Bull Seismol Soc Am 73:18651894

15) Boore DM (1996) SMSIM - Fortran programs for simulating ground motions from earthquakes: Version 1.0. US Geol Surv Open-file Rep, p 73

16) Boore DM (2003) Simulation of ground motion using the stochastic method. Pure Appl Geophys 160:635-676

17) Borja-Navarrette, Diaz-Canales GM, Vera AV, Valle-Calderon ED (1986) Damage statistics of the September 19, 1985, Earthquake in Mexico City. ASCE 70-77

18) Cornell CA (1968) Engineering seismic risk analysis. Bull Seismol Soc Am 58:1583-1606

19) Fortheringham SA, Wegener M (2000) Spatial models and GIS, new potential and new models. Taylor \& Francis, London, 8-10

20) Hough SE, Borcherdt RD, Friberg PA, Busby R, Field EF, Jacob KH (1990) Sediment-induced propagation and the collapse of the Nimitz freeway. Nature 344:853-855

21) Hume WE (1911) The effect of secular oscillation in Egypt during the Cretaceous and Eocene periods. Quart J Geol Soc 67:118-148

22) Hussein HM, Korrat IM, Abdel-Fattah AK (1996) The October 12, 1992 Cairo earthquake a complex multiple shock. Bull Int Inst Seism Earthq Eng (IISEE) 30:921

23) Hussein HM (1999) Source process of the October 12, 1992 Cairo Earthquake. Annali Di Geofisica 42: p4

24) Hussein HM, Farouk MA (2000) Spectral analysis and scaling relations of Cairo Earthquake sequence of Oct. 12, 1992 recorded at KEG VBB Station. ICEHM2000, Cairo University, Egypt, 102-117

25) Joshi A, Mohan K, Patel RC (2007) A deterministic approach for preparation of seismic hazard maps in North East India. Nat Hazards 43:129-146

26) Khaled O, Mohsen A, El-Sayed F, Awad H, Hussein E (2013) Modeling of strong ground motion during the 1992 Cairo earthquake in the urban area northern Greater of Cairo, Egypt. NRIAG Journal of Astronomy and Geophysics 2:166-174 
27) McGuire R (2008) Probabilistic seismic hazard analysis: Early history. Earthq Eng Struct Dyn 37:329-338

28) McGuire RK (1995) Probabilistic seismic hazard analysis and design earthquakes: closing the loop. Bull Seismol Soc Am 85:1275-1284

29) Midorikawa S, Matsuoka M, Sakugawa K (1994) Site effects on strong-motion records observed during the 1987 Chiba-ken Toho-oki Japan earthquake. In proc of 9th Japan Earthquake Eng Symp 3:85-90

30) Midorikawa S (2006) Some problems related to empirical predictions of strong motion. Bull Earthq Res Inst Univ Tokyo 81:253-258

31) Mohamed AA, El-hadidy M, A. Abou-Elenean KM (2012) Seismic hazard studies in Egypt. NRIAG J Astron Geophys 1:119-140

32) Mustafa Sayed SR and Takenaka H (2009) Stochastic ground motion simulation of the 12 October 1992 Dahshour earthquake. Acta Geophysica 57:636-656

33) Ordaz MG, Cardona OD, Salgado-Gálvez MA, Bernal-Granados GA, Singh SK, Zuloaga-Romero D (2014) Probabilistic seismic hazard assessment at global level. Int J Disaster Risk Reduct 10:419-427

34) Rathje EM, Stokoe IKH, Rosenblad B (2003) Strong motion station characterization and site effects during the 1999 earthquakes in Turkey. Earthquake Spectra 19:653-675

35) Rathje EM, Kockar M, Ozbey MC (2005) Observed site effects during the 1999 Chi-Chi Earthquake and its aftershocks. Bull Seismol Soc Am 76: p 238

36) Sabet H, Saad A, Abd-Elhamied F (2015) Geotechnical study at 15 May City, Cairo, Egypt. Int J Innovative Sci Eng Tech 2(8):960-977

37) Said R (1962) The Geology of Egypt. Amsterdam London, New York, p 377

38) Said R, Martin L (1964) Cairo area geological excursion notes. In Proc of Pert Expl Soc Liya, 107-121

39) Si H, Midorikawa S (1999) Attenuation relations for peak ground acceleration and velocity considering effects of fault type and site condition. J Struct Construct Eng $523: 63-70$

40) Thenhaus PC, Sharp RV, Celebi M, Ibrahim ABK, Van-de-Pol H (1993) Reconnaissance report on the 12 October 1992 Dahshour, Egypt, Earthquake. US Geol Surv Open-file Rep, 93-181 
41) Wen RZ, Ren YF, Zhou ZH, Shi DC (2010) Preliminary site classification of free592 field strong motion stations based on Wenchuan earthquake records. Earthq Sci

593 23:101-110

594

595

596

597

598

599

600

601

602

603

604

605

606

607

608

609

610

611

612

613

614

615

616

617

618

619

620

621 


\section{Statements and Declarations}

623 a) Funding

624 The authors declare that no funds, grants, or other support were received during the 625 preparation of this manuscript.

626

627 b) Competing Interests

628 The authors have no relevant financial or non-financial interests to disclose.

629

630 c) Author Contributions

631 All authors contributed to the study's conception and design. Material preparation and 632 data collection were performed by Ibrahim Djamaluddin and Ahmed M. Meneisy.

633 Interpretation of data and analysis were performed by Ibrahim Djamaluddin and Poppy

634 Indrayani. The first draft of the manuscript was written by Ibrahim Djamaluddin and all 635 authors commented on previous versions of the manuscript. All authors read and 636 approved the final manuscript.

637

638

639

640

641

642

643

644

645

646

647

648

649

650

651

652 


\section{Table captions}

654

Table 1 NEHRP site definition in terms of Vs30 and simple geological descriptions

656

657 Table 2 Simulated surface velocity at MMI level areas for October 12, 1992, Dahshour

658 earthquake

659

660

661 Figure captions

662

663 Fig. 1 Location map of the study area

664

665 Fig. 2 Selected earthquakes beneath southwestern Cairo from 1990 to 2018 from the

666 USGS world database of earthquakes

667

668 Fig. 3 Geological map of the study area (after the Egyptian General Petroleum 669 Corporation, 1987) and colored shaded relief map overlaid the extracted lineaments (solid 670 red lines)

671

672 Fig. 4 Fault modeling algorithm using GIS functions

673

674 Fig. 5a Schematic flow diagram analysis for automatic computation of 3D fault model 675 using GIS geoprocessing tools

676

677 Fig. 5b 3D view of the 3D fault modeling result from the selected lineaments covering 678 an area about $100 \mathrm{~km}^{2}$ with detailed structural interpretation involves extruding the fault 679 surfaces and fault orientations that overlaid with a 3D grid-mesh system

680

681 Fig. 6 Estimated ground motion propagation map from the average shear-wave velocity 682 and soil susceptibility map

683 
684 Fig. 7 3D calculation modeling algorithm using GIS functions to calculate the seismic 685 hazard by the attenuation relationships

686

687 Fig. 8 Illustration of shortest distance from a 3D surface point (A) to the fault plane (P)

688

689 Fig. 9 Modified Mercalli Intensity (MMI) distribution map of October 12, 1992,

690 Dahshour earthquake (after Thenhaus et al. 1993), and study area (red dotted lines)

691

692 Fig. 10a Simulation of surface velocity distribution map of October 12, 1992, Dahshour

693 earthquake overlaid with the MMI observation contours and the identified seriously

694 damaged areas

695

696 Fig. 10b Simulation of seismic intensity distribution map of October 12, 1992, Dahshour

697 earthquake overlaid with the MMI observation contours and the identified seriously

698 damaged areas

699

700 Fig. 11a Simulation of surface velocity distribution map of expected 6.5 magnitudes

701 Dahshour earthquake

702

703 Fig. 11b Simulation of seismic intensity distribution map of expected 6.5 magnitudes

704 Dahshour earthquake

705

706 Fig. 12a Simulation of surface velocity distribution map of October 11, 1999, Beni Suef

707 earthquake

708

709 Fig. 12b Simulation of seismic intensity distribution map of October 11, 1999, Beni Suef

710 earthquake

711

712

713

714

715 


\section{Tables}

717

718 Table 1 NEHRP site definition in terms of AVS and simple geological descriptions

719

\begin{tabular}{l|l|l}
\hline NEHRP & Description & Range of AVS (m/s) \\
\hline A & Hard rock & AVS $>1500$ \\
B & Firm to hard rock & $1500 \geq$ AVS $>760$ \\
C & Dense soil and soft rock & $760 \geq$ AVS $>360$ \\
D & Stiff soil & $360 \geq$ AVS $>180$ \\
E & Soft soil & $180 \geq$ AVS \\
\hline
\end{tabular}

720

721 Table 2 Simulated surface velocity at MMI level areas for October 12, 1992, Dahshour

722 earthquake

\begin{tabular}{lcccccc}
\hline & \multicolumn{2}{c}{ Isoseismal map } & \multicolumn{4}{c}{ Simulation map } \\
\hline \multirow{2}{*}{ Scale level } & $\begin{array}{c}\text { Velocity } \\
\text { range }(\mathrm{cm} / \mathrm{s})\end{array}$ & Potential damage & \multicolumn{4}{c}{ Velocity distribution at each MMI level } \\
\cline { 4 - 7 }$(\mathrm{cm} / \mathrm{s})$ & \multicolumn{4}{c}{ Max } & Sdv \\
\cline { 3 - 7 } & $3.4-8.1$ & Very light & 3.31 & 0.83 & 6.67 & 1.10 \\
\hline V. Moderate & $8.1-16$ & Light & 8.89 & 3.15 & 17.93 & 2.63 \\
VI. Strong & $16-31$ & Moderate & 18.16 & 7.95 & 30.78 & 4.69 \\
VII. Very strong & $31-60$ & Moderate to heavy & 32.71 & 15.24 & 52.96 & 8.79 \\
VIII. Severe & & & & &
\end{tabular}

723

724

725

726

727

728

729

730

731

732

733

734

735

736

737 


\section{Figures}

739

740

741

742

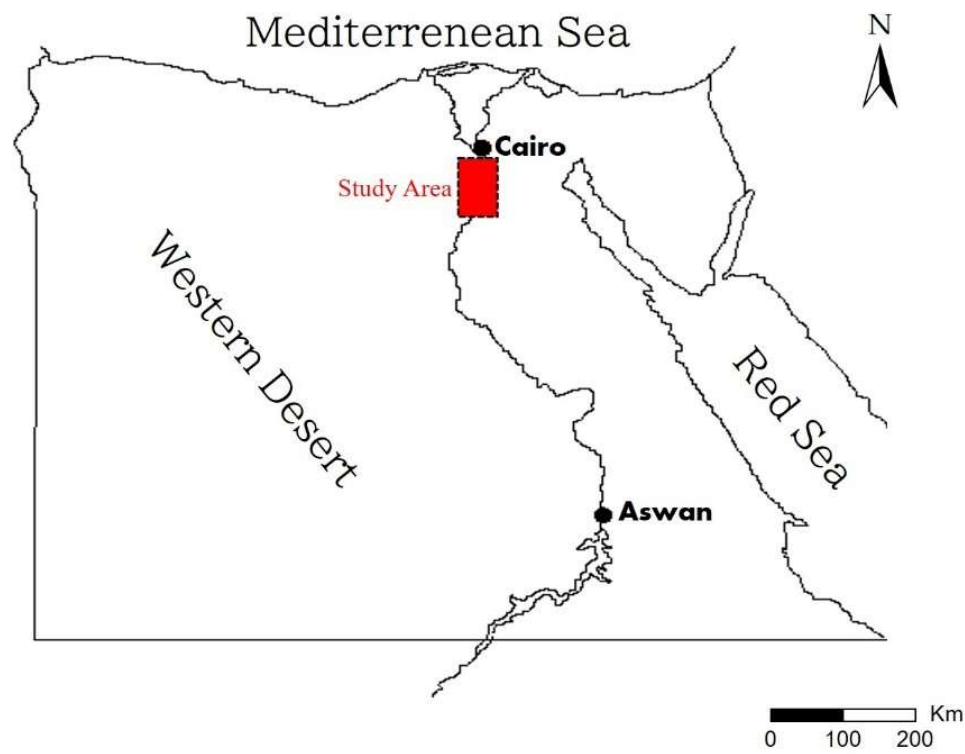

Fig. 1 Location map of the study area

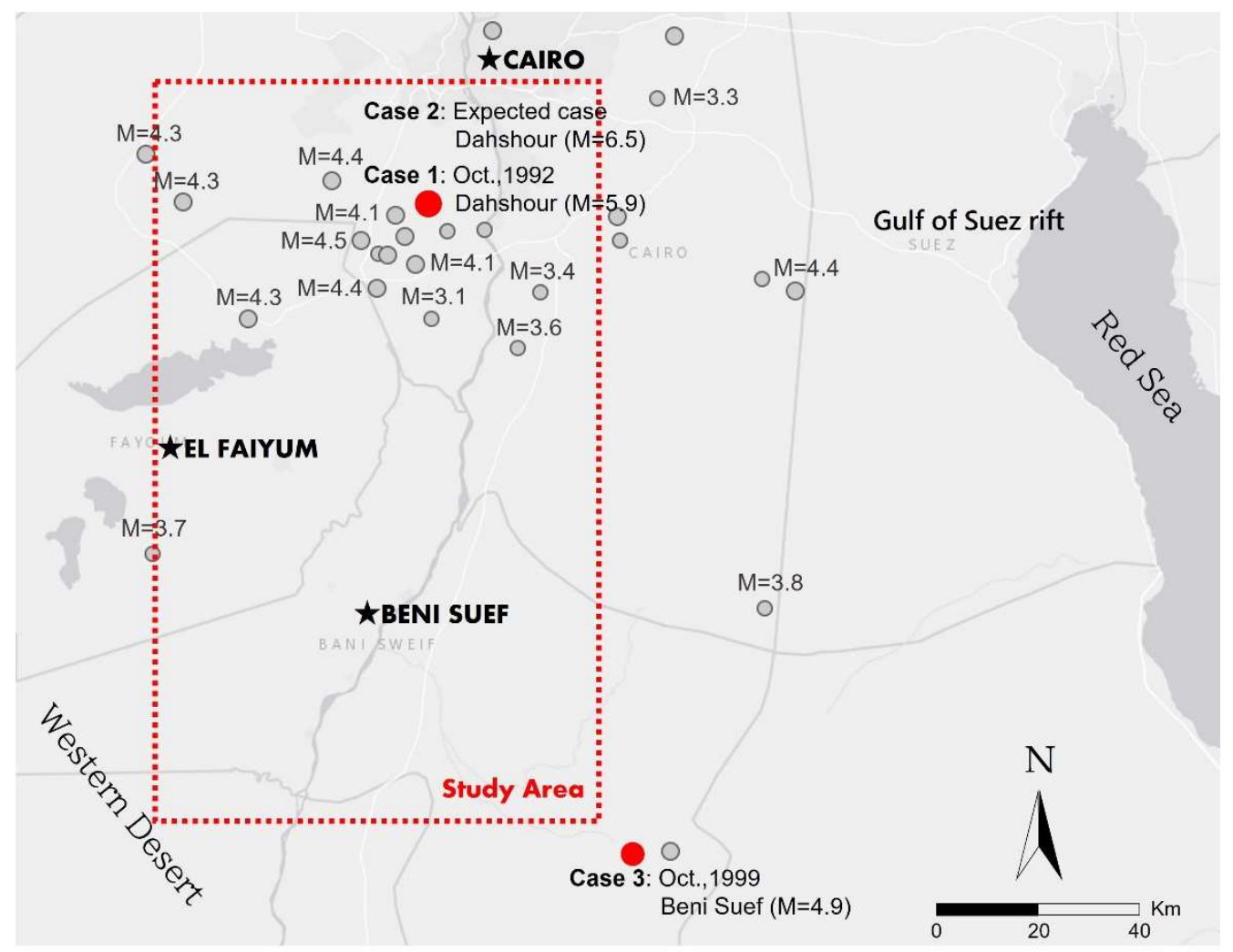

Fig. 2 Selected earthquakes beneath southwestern Cairo from 1990 to 2018 from the 


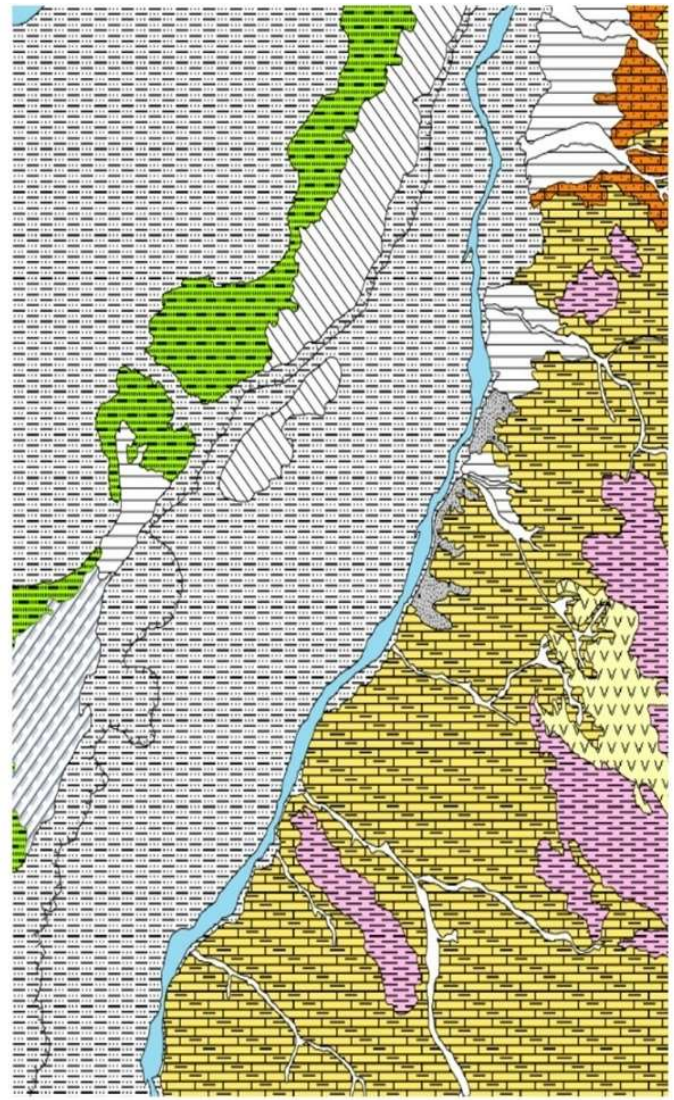

\section{Legend}

\begin{tabular}{|c|c|c|c|}
\hline & Fanglomerate & 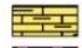 & Mokattam Group \\
\hline & Protonile deposits & & Beni Suef Formation \\
\hline & Prenile deposits & & Wadi Rayan Formation \\
\hline 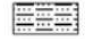 & Nile silt & & Pliocene deposits \\
\hline & Wadi deposits & 垔 & Kom el Shelul Formation \\
\hline$v v$ & Maadi Formation & & Water \\
\hline & & & Canal \\
\hline
\end{tabular}
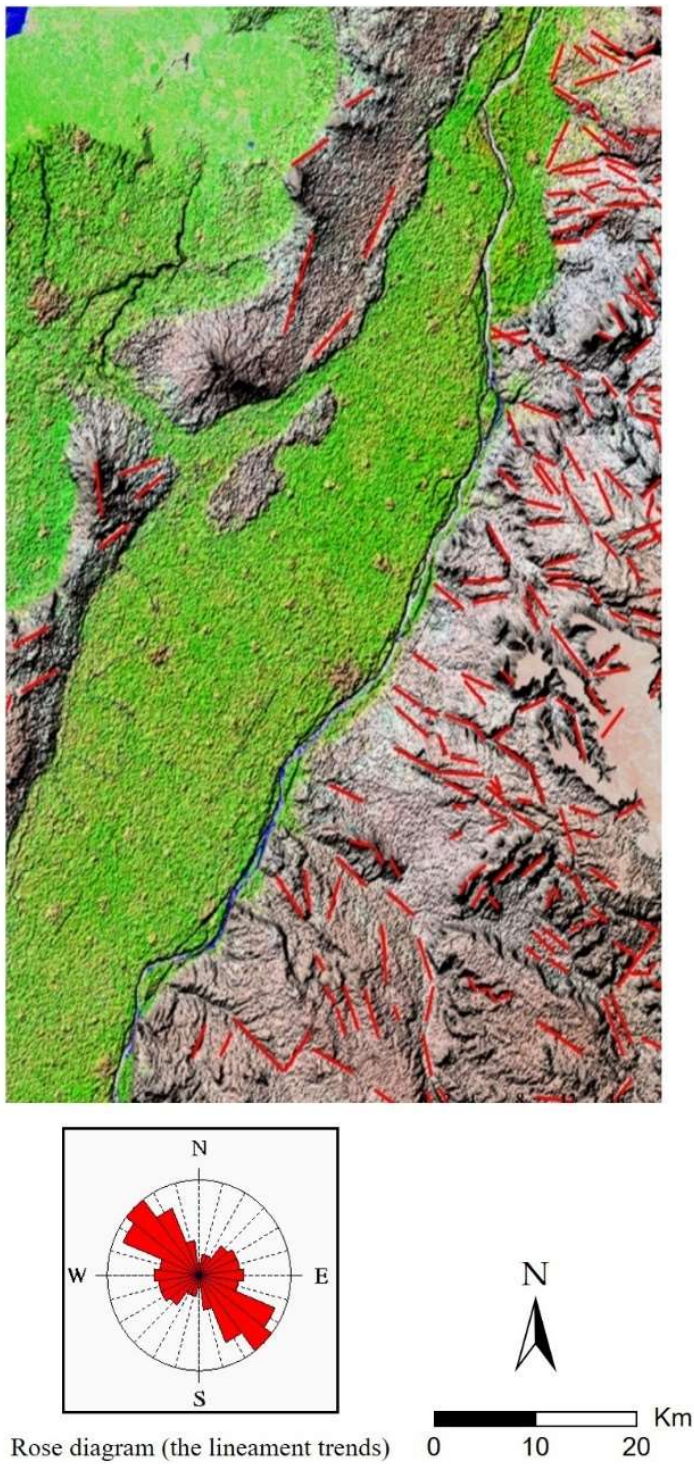

Fig. 3 Geological map of the study area (after the Egyptian General Petroleum

Corporation, 1987) and colored shaded relief map overlaid the extracted lineaments

(solid red lines) 


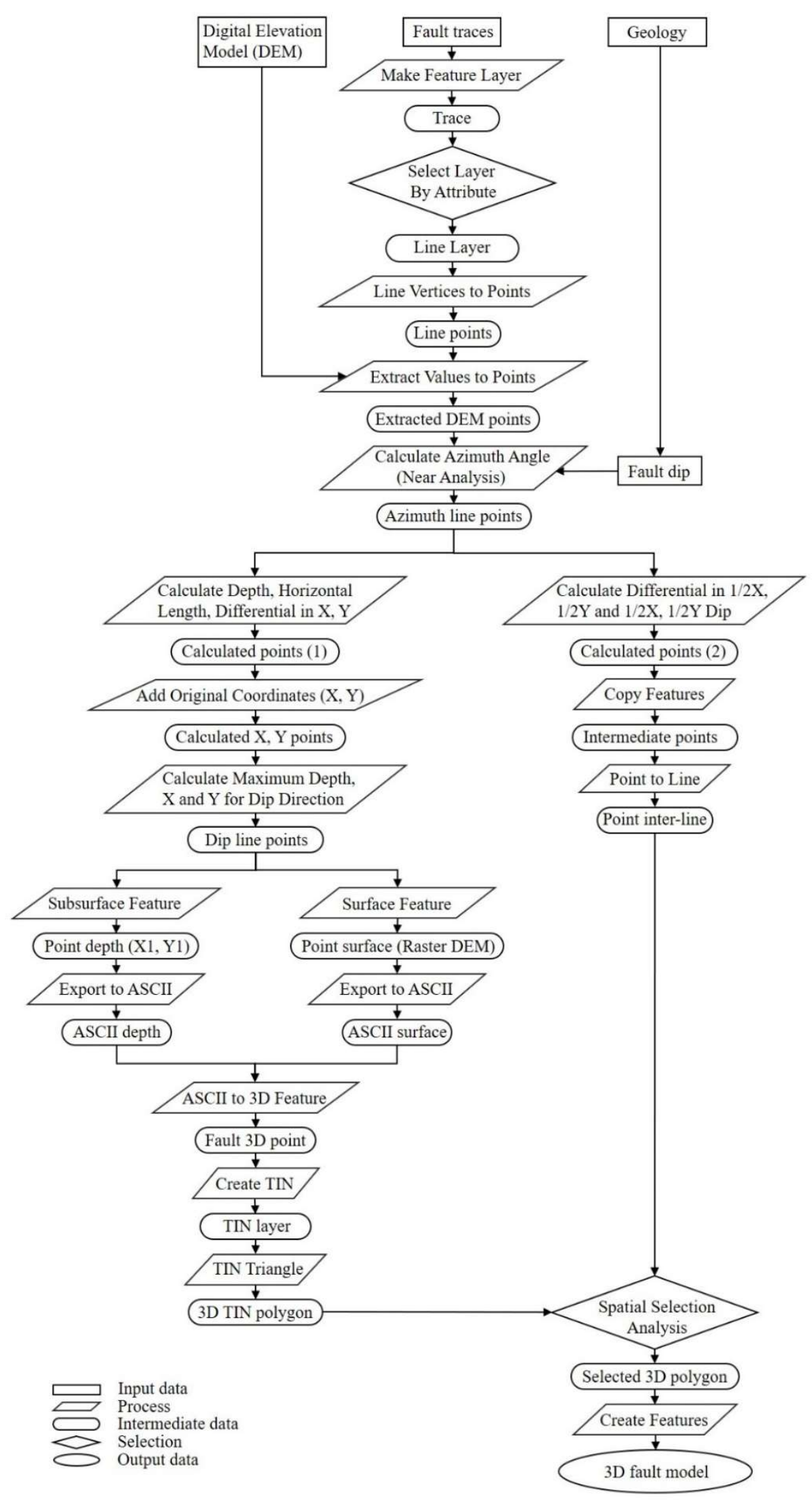

Fig. 4 Fault modeling algorithm using GIS functions 


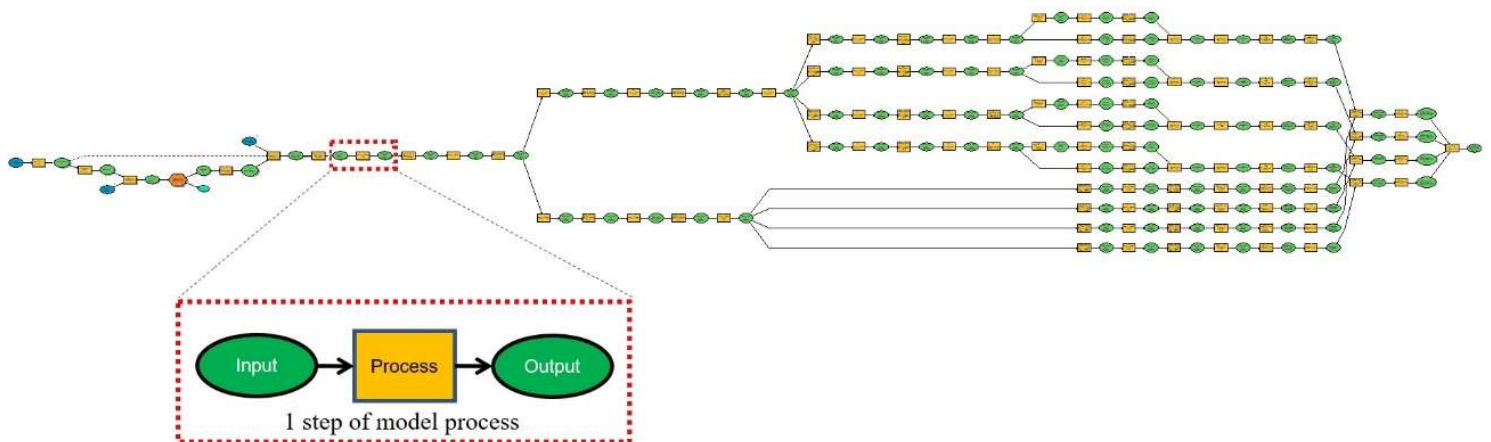

Fig. 5a Schematic flow diagram analysis for automatic computation of 3D fault model using GIS geoprocessing tools

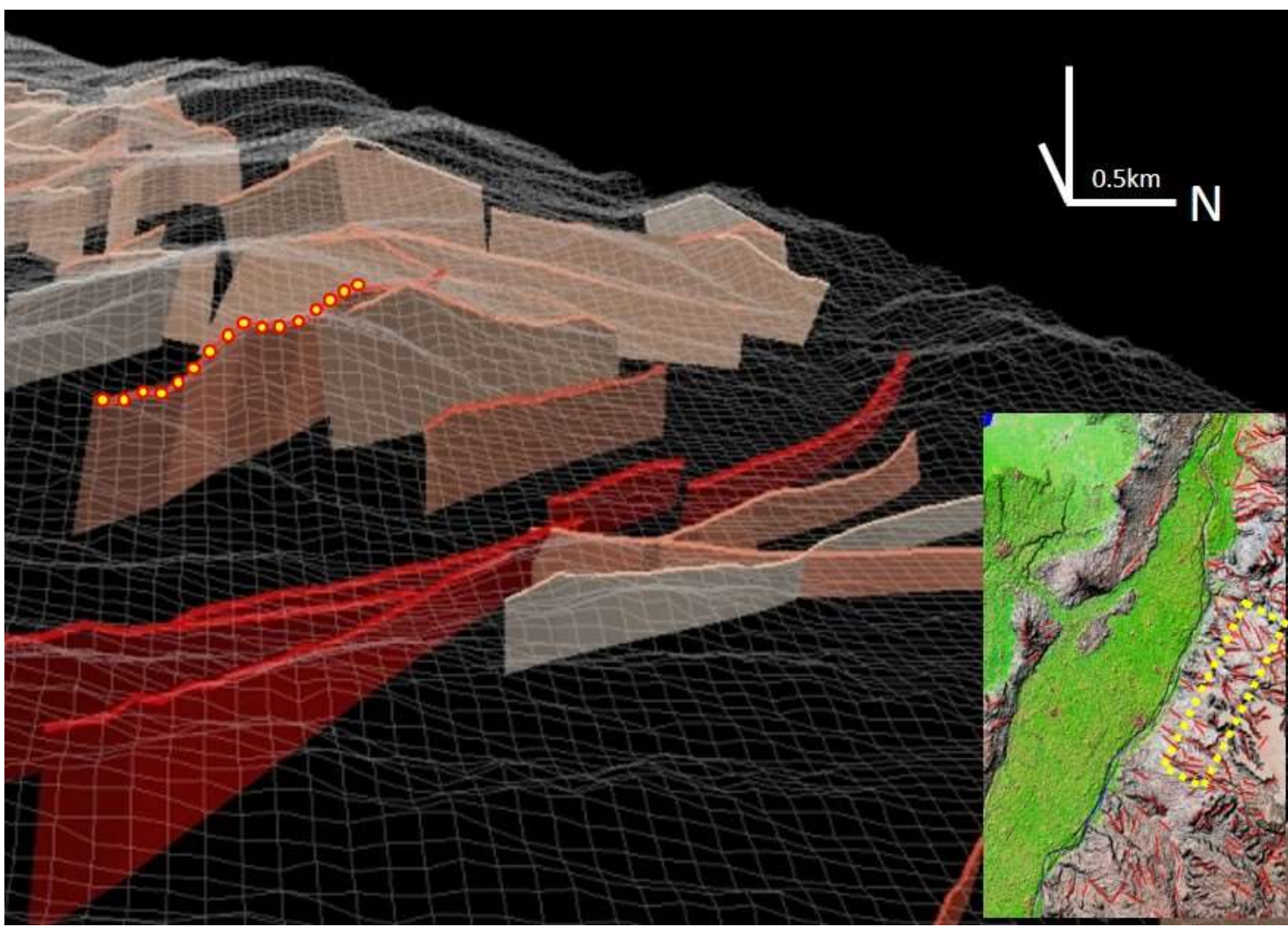

Fig. 5b 3D view of the 3D fault modeling result from the selected lineaments covering an area about $100 \mathrm{~km}^{2}$ with detailed structural interpretation involves extruding the fault surfaces and fault orientations that overlaid with a 3D grid-mesh system 


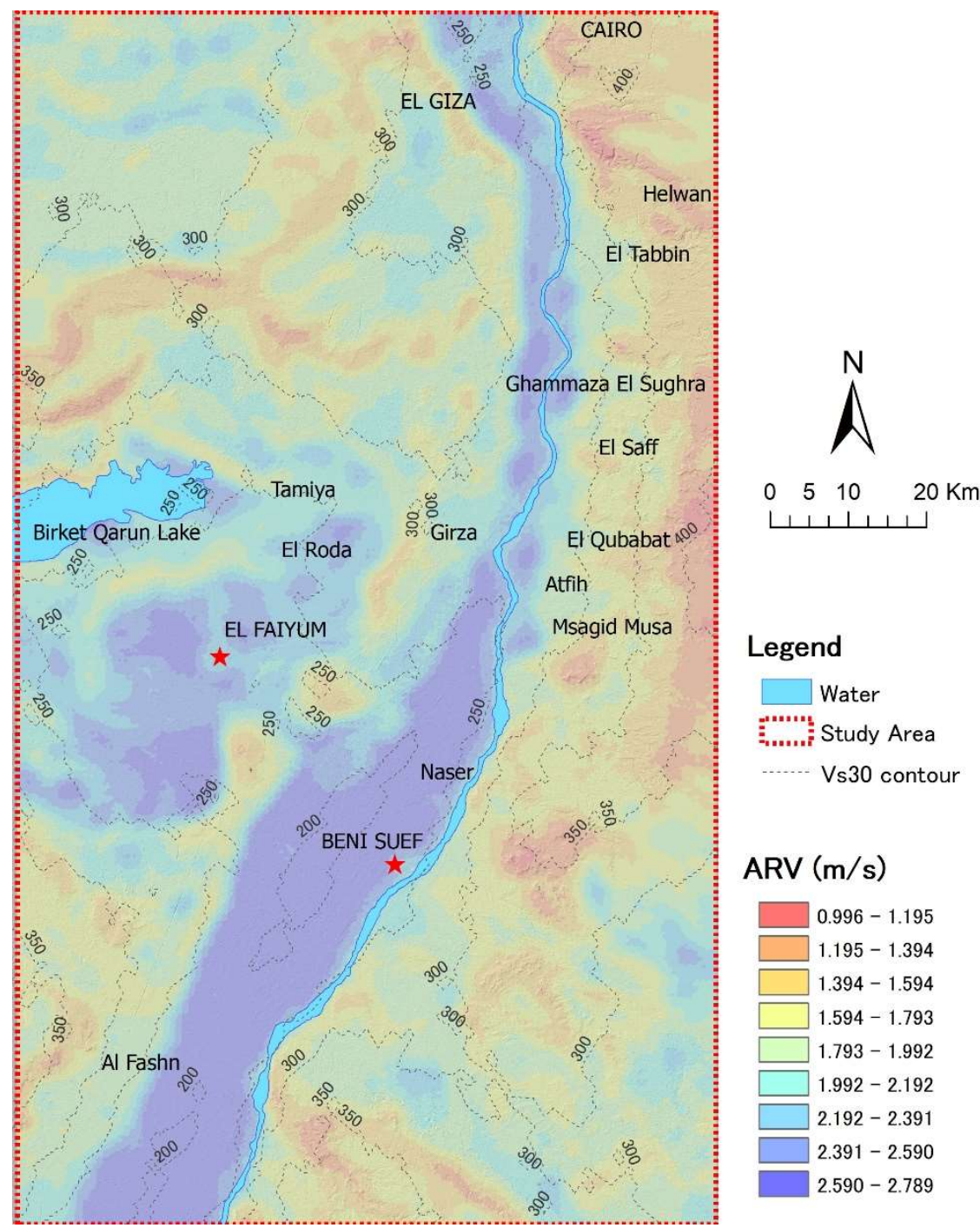

763 Fig. 6 Estimated ground motion propagation map from the average shear-wave velocity and soil susceptibility map 


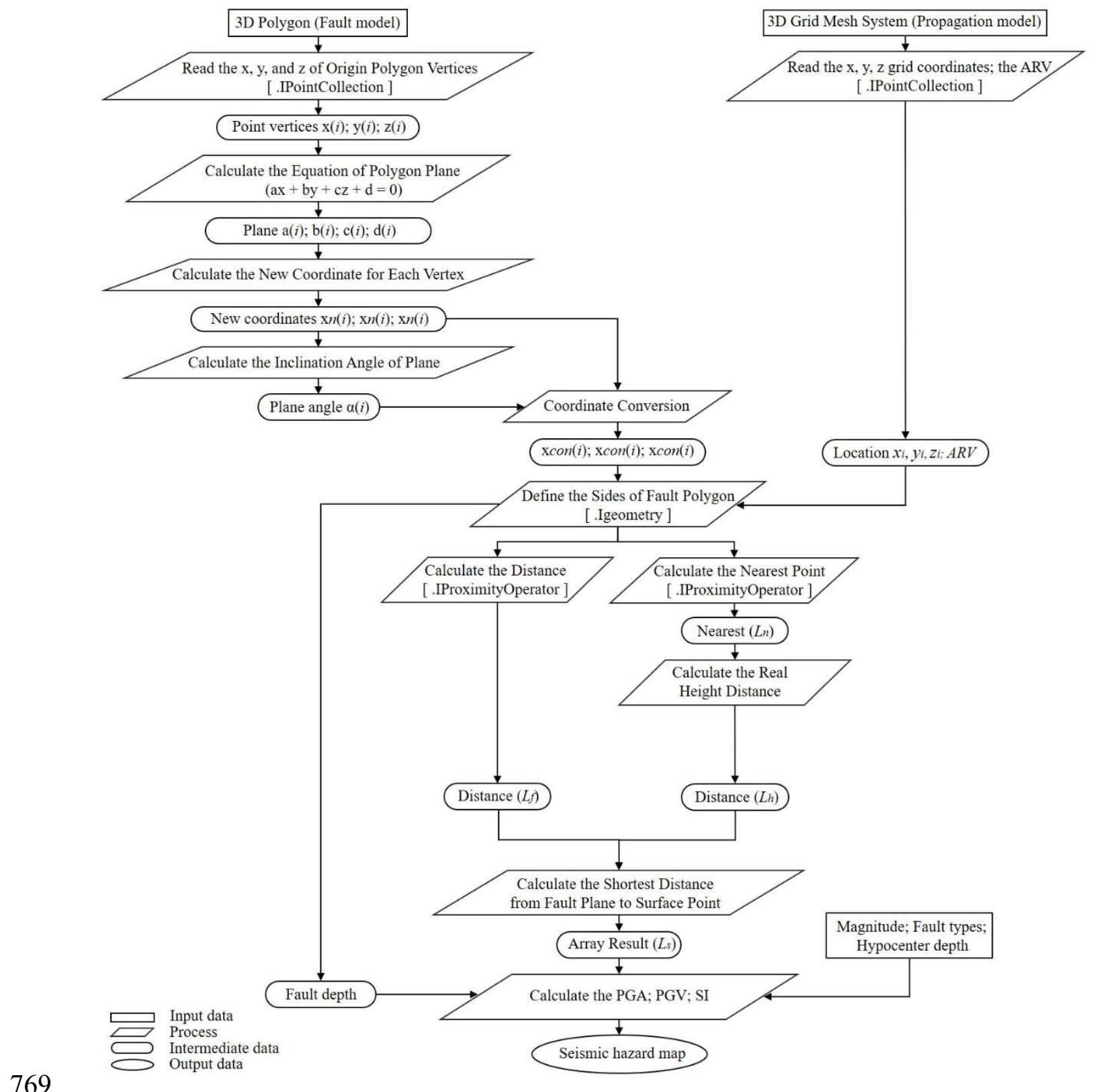

Fig. 7 3D calculation modeling algorithm using GIS functions to calculate the seismic 


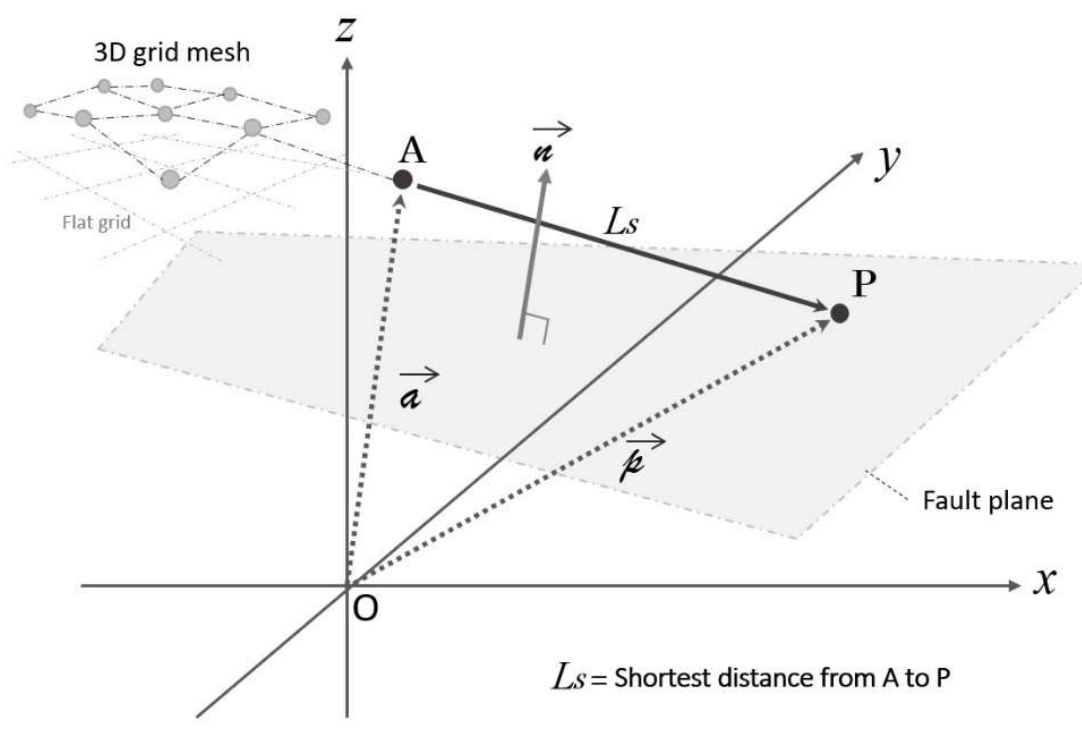

774 Fig. 8 Illustration of shortest distance from a 3D surface point (A) to the fault plane (P)

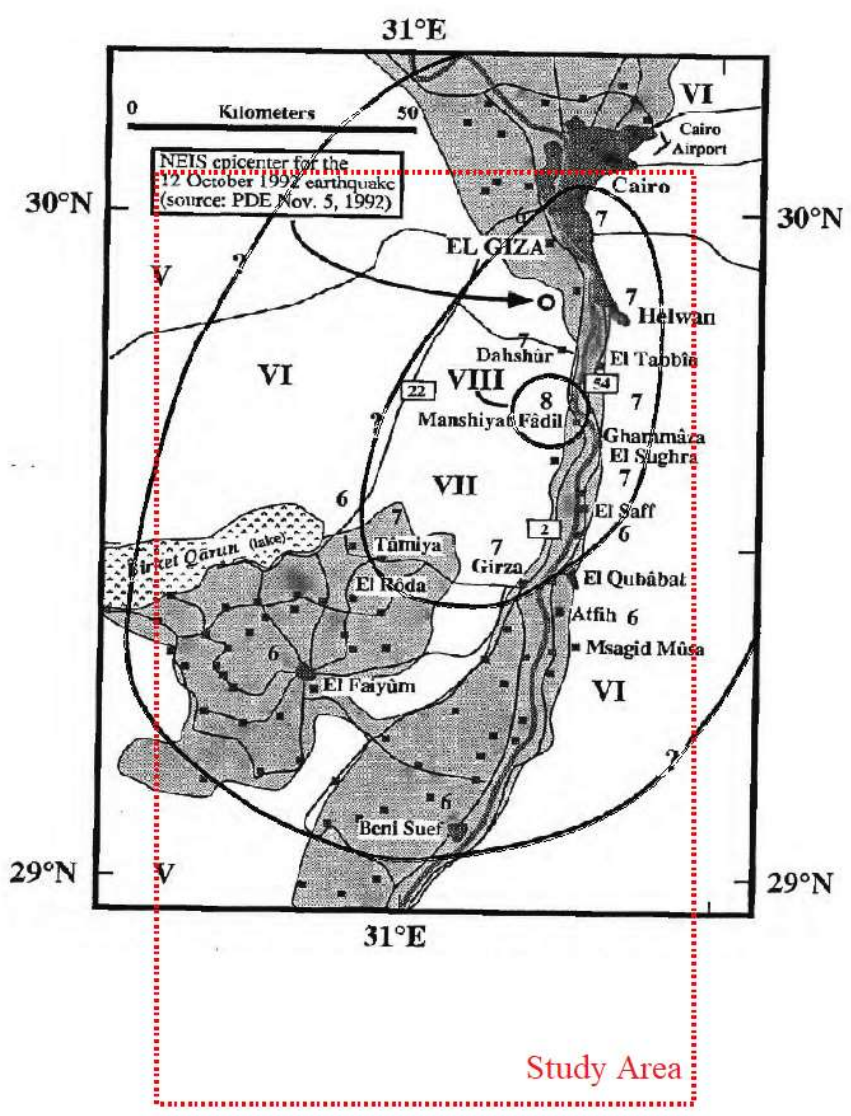

777 Fig. 9 Modified Mercalli Intensity (MMI) distribution map of October 12, 1992,

778 Dahshour earthquake (after Thenhaus et al. 1993), and study area (red dotted lines) 


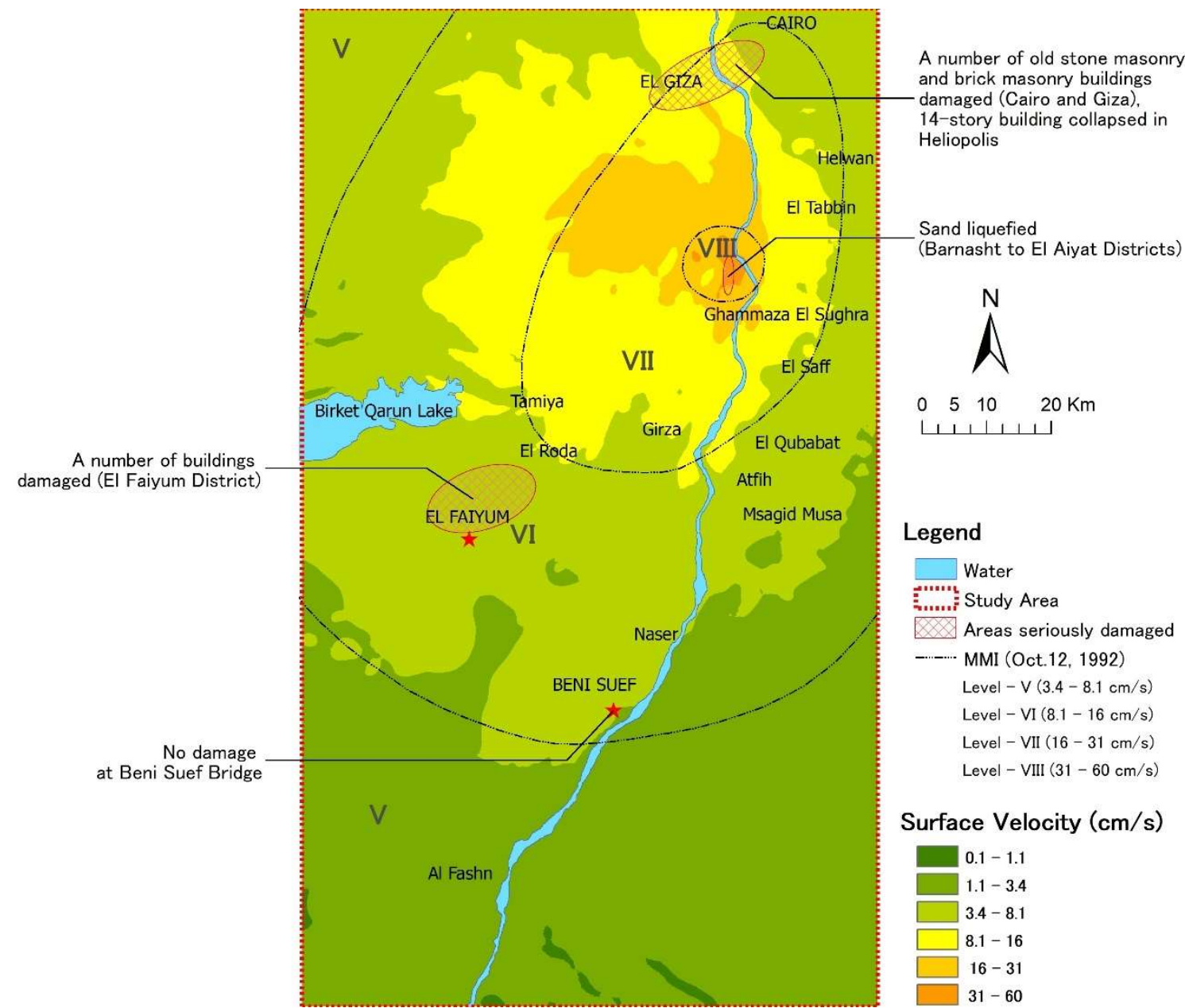

780 Fig. 10a Simulation of surface velocity distribution map of October 12, 1992, Dahshour 


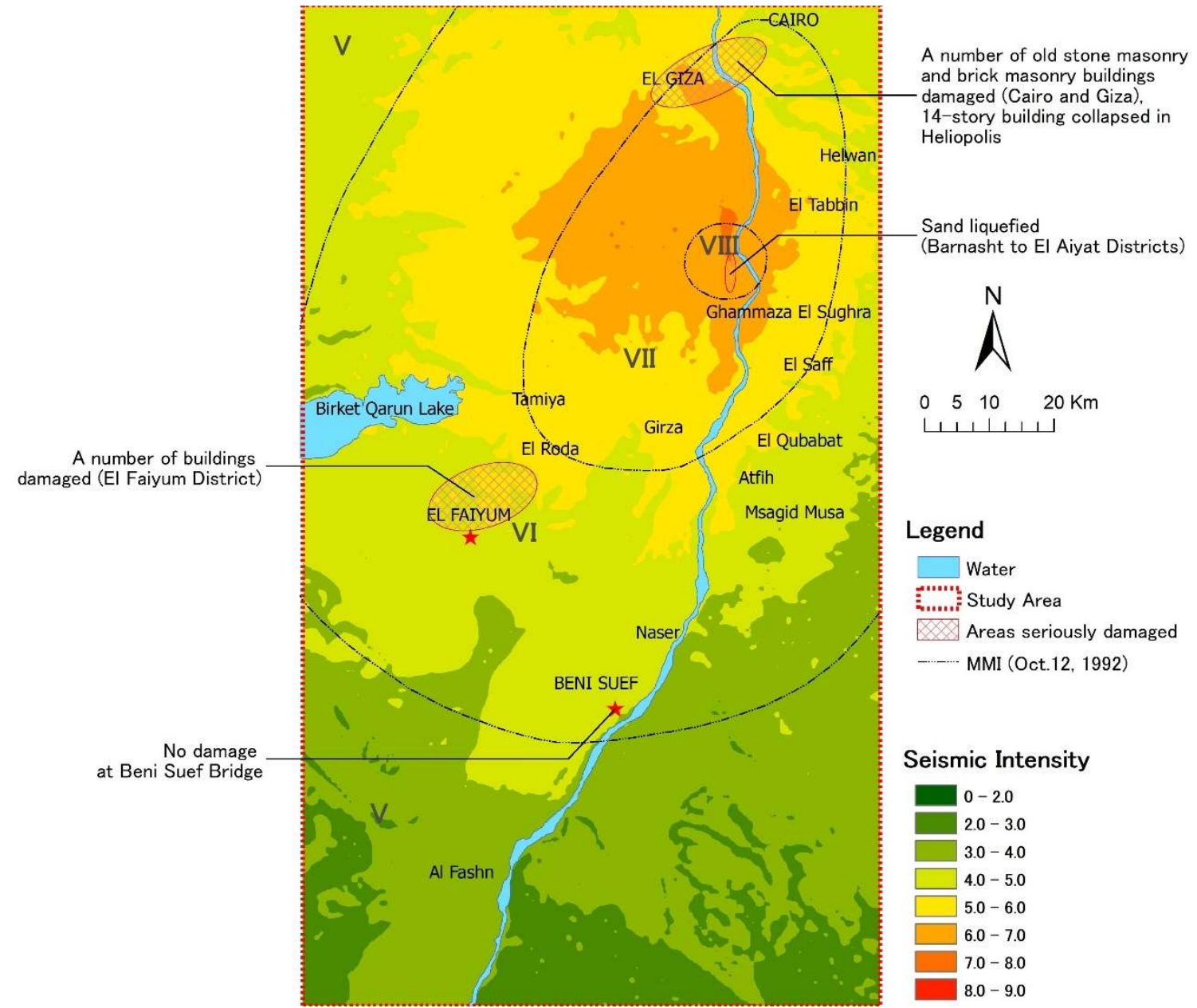

Fig. 10b Simulation of seismic intensity distribution map of October 12, 1992, 

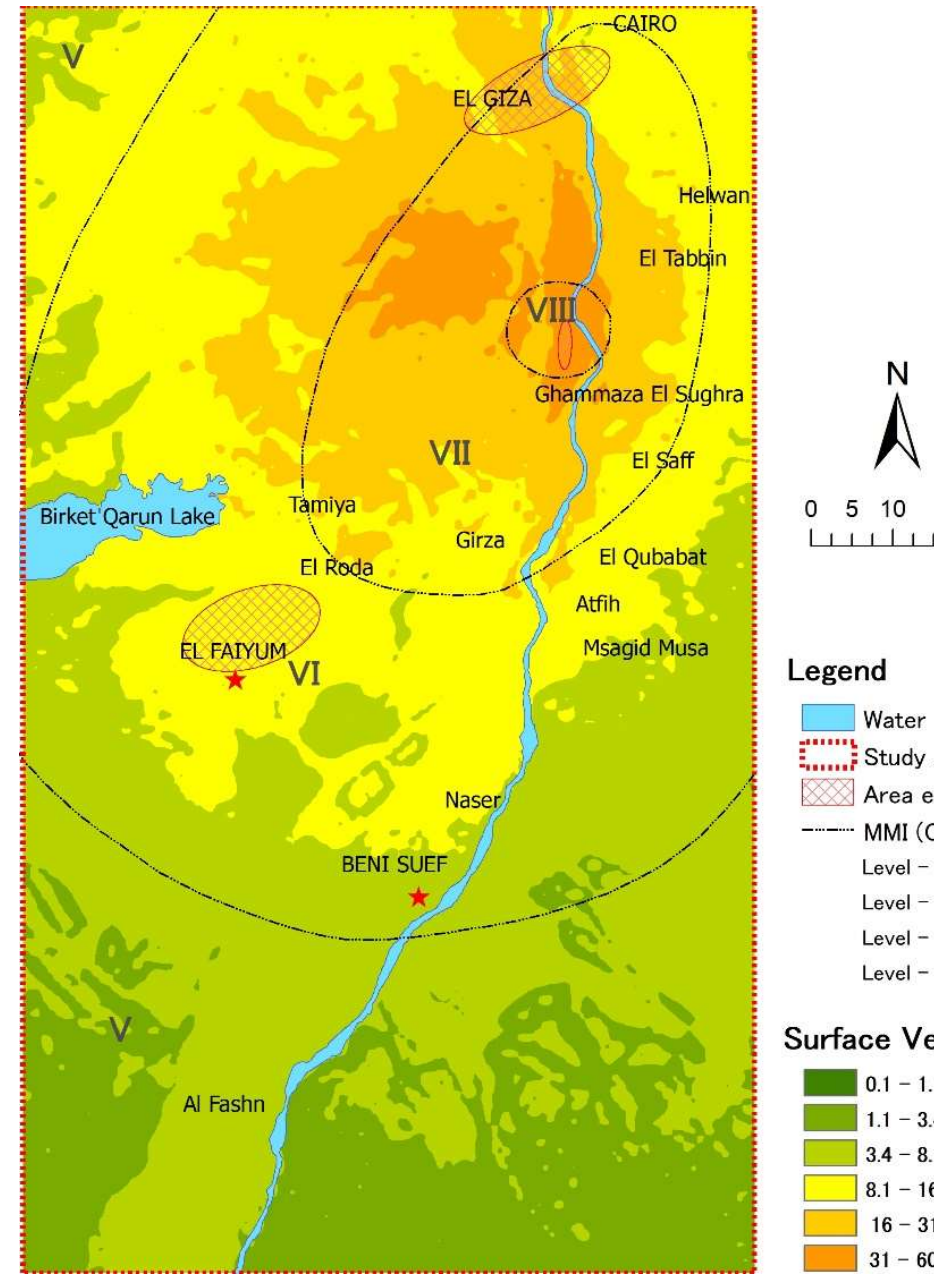

$\begin{array}{lll}0 & 510 \quad 20 \mathrm{Km}\end{array}$

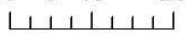

Legend

W Water

:.......... Study Area

Area experienced damage

MMI (Oct.12, 1992)

Level - V $(3.4-8.1 \mathrm{~cm} / \mathrm{s})$

Level - VI $(8.1-16 \mathrm{~cm} / \mathrm{s})$

Level - VII $(16-31 \mathrm{~cm} / \mathrm{s})$

Level - VIII $(31-60 \mathrm{~cm} / \mathrm{s})$

Surface Velocity $(\mathrm{cm} / \mathrm{s})$

Fig. 11a Simulation of surface velocity distribution map of expected 6.5 magnitudes

Dahshour earthquake 


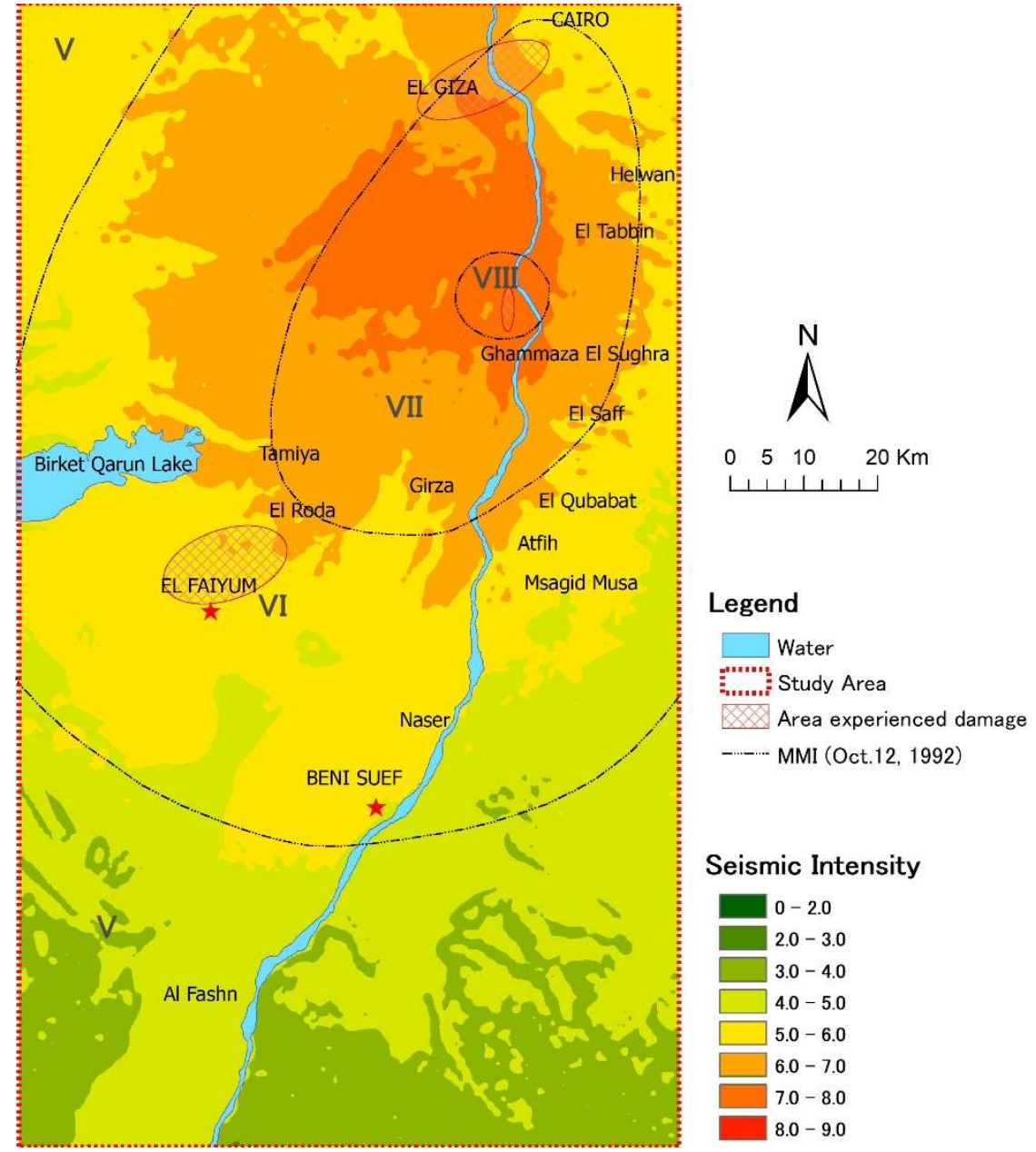

Fig. 11b Simulation of seismic intensity distribution map of expected 6.5 magnitudes 

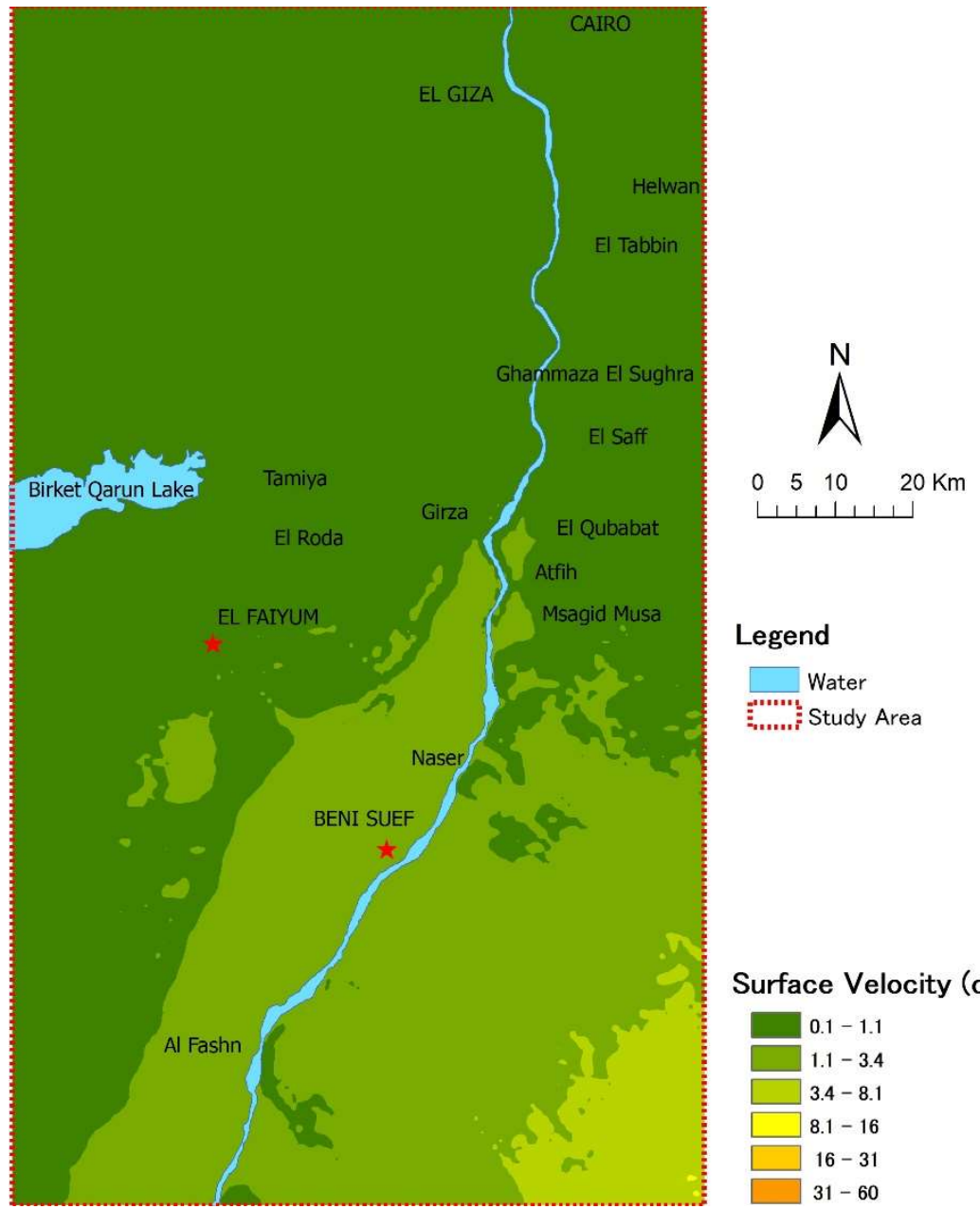

Legend

Water

:......... Study Area

Surface Velocity $(\mathrm{cm} / \mathrm{s})$

800 Fig. 12a Simulation of surface velocity distribution map of October 11, 1999, Beni Suef 801 earthquake 


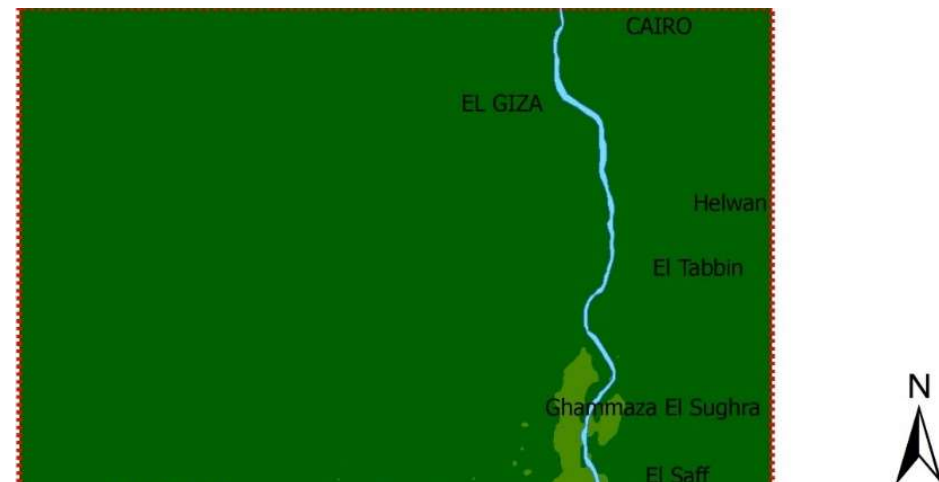

804 Fig. 12b Simulation of seismic intensity distribution map of October 11, 1999, Beni 805 Suef earthquake

806 